\title{
Exploration and Practice of Postgraduate Academic Meeting for Innovation and Expression Ability Cultivation
}

\author{
Wenzheng Cui, Jianguo Yang*, Bo Lin, Zhaoying Zhang, Anyu Meng \\ School of Automotive Engineering, Harbin Institute of Technology at Weihai, Weihai, China \\ Email address: \\ cuiwenzheng@hit.edu.cn (Wenzheng Cui), yangjianguo@hitwh.edu.cn (Jianguo Yang)

\section{To cite this article:} \\ Wenzheng Cui, Jianguo Yang, Bo Lin, Zhaoying Zhang, Anyu Meng. Exploration and Practice of Postgraduate Academic Meeting for \\ Innovation and Expression Ability Cultivation. Science Journal of Education. Vol. 7, No. 1, 2019, pp. 30-35. \\ doi: $10.11648 /$ j.sjedu.20190701.16
}

Received: April 16, 2019; Accepted: May 20, 2019; Published: May 23, 2019

\begin{abstract}
The establishment of an academic platform is crucial for graduate education. This paper explores and practices the conference from four aspects: enhancing the critical thinking ability of graduate students, writing and oral expression skills, communication skills and the enthusiasm of graduate students to participate in the conference. This paper mainly has the following contents: Organizational Link Design, Teacher-student participation model research, Review indicator system and measurement research, Incentive design, Design of academic exchange platform. In the conference participation mode, the teacher and the students participate together, and the students are the main participants of the conference; in the evaluation index system and the measurement research, the combination of qualitative and quantitative research is adopted. In qualitative evaluation, it evaluates from six aspects: the topic selection, verbal ability, article normativeness, article innovation, written expression ability and communication ability. In quantitative evaluation, it is reflected in the final "level" of the paper. In the design of the incentive method, based on Herzberg's two-factor theory and Skinner's reinforcement theory. In the design of the academic communication platform, the combination of online and offline is adopted. The results showed that the design for the academic conference is successful. However, it should be enhanced on paper reviewing process when the next meeting is prepared because some graduate students are not so much experienced on reviewing manuscripts.
\end{abstract}

Keywords: Postgraduate Student, Academic Exchange, Expression Ability

\section{Introduction}

Postgraduate academic exchanges mainly refer to the gatherings, discussions, reports and other activities involving graduate students involved in the frontier fields, new theories and new methods of relevant disciplines. This is an important part of postgraduate training and the main way to encourage postgraduate innovation. World-class universities attach importance to the academic exchange activities of graduate students. Through academic exchange activities, they can cultivate students' critical thinking, Writing and expression skills, communication skills, strengthen teacher-student interaction, promote interdisciplinary interaction, and stimulate innovative thinking. This is an important measure to train high-quality talent.

The success of postgraduate education in developed countries is due to their emphasis on academic exchanges. Based on a large number of open seminars, seminars, academic conferences, lectures, etc., Harvard University attaches great importance to the creation of an academic atmosphere. Each year, hundreds of visiting scholars who undertake research tasks at Harvard University's colleges participate in academic activities. The relaxed and free academic atmosphere of Cambridge University has become an "incubator" for its outstanding academic achievements.. Australia's National ICT of Australia also held a number of student conferences, which have played a good role in the cultivation of graduate students' innovative ability and expression ability. The University of Tokyo encourages graduate students to participate in international collaborative research. Through collaborative research, students develop their horizons on the one hand, and exercise their expressive and communication skills in the process of communicating with others.

China is a big country for postgraduate education. In order to promote postgraduate education, the Ministry of Education proposed the "Graduate Education Innovation Plan" in 2002 and included the "2003-2007 National Education 
Revitalization Action Plan", from the implementation goals and requirements of the Graduate Education Innovation Program. In view of this, the academic exchange activities of graduate students and the construction of communication platforms are necessary conditions for the realization of this plan. Tsinghua University began to hold a doctoral academic forum in March 2002, and held a total of 125 issues by the end of 2006. The number of participants and the number of academic reports are very impressive. Well-known universities such as Peking University and Fudan University are also examples of the construction of academic exchange platforms for graduate students. As of 2005, Fudan University has established cooperation and exchanges with more than 200 institutions of higher learning and scientific research institutions in nearly 30 countries and regions. In 2013, Peking University, Fudan University, University of Science and Technology of China, Nanjing University, and Tsinghua University established the University Alliance of China's first-level key disciplines in physics. Since 2014, the five schools have taken turns to host inter-academic alliance doctoral students' forums, which have been held for three times, and each time they can attract more than 100 teachers and students from five schools to carry out academic exchanges. All colleges and universities have achieved some good results through academic exchange activities.

Various scholars have also put forward some suggestions on academic exchange activities and related issues. Zhaohui Chu [1] puts forward some questions that should be paid attention to when designing graduate academic activities. Wenjie Shen and Qiang Zhu [2] analyzed the application of Seninar teaching method in postgraduate teaching. Fischer et al. [3] found theoretical contributions (original) from the perspective of reviewing experts, method accuracy, conceptual accuracy, discussion of results, length/contribution ratio, processing of related literature, theoretical contribution (modified), logical structure, clarity of research purposes, readability and significance of research topics, etc. 11 items are the most important. Literature [4, 5] mainly discusses the incentive mechanism; the literature [6-10] mainly discusses how the academic platform should be established; Yuying Xiong [11] explores the significance of academic exchange activities; Ya Zhao [12] explores how to create a good academic atmosphere for graduate students; Lingfang $\mathrm{Hu}$ [13] Researched how to make reasonable evaluations of academic papers in different disciplines.

Although all kinds of postgraduate academic exchange activities in China have achieved good results in terms of innovation ability training, there are still some shortcomings compared with foreign high-level universities and research institutions.

Firstly, the cultivation of critical thinking ability needs to be strengthened. Secondly, the written and oral expression, as well as the communication ability training needs to be strengthened. Finally, the degree of participation of graduate students needs to be further strengthened. The organizational model, participation model, and evaluation index system of academic exchange meetings need to be improved. Based on these shortcomings, the research design of this paper is proposed.

\section{Methods}

The theory of this paper mainly includes Seminar-style teaching method, the combination of qualitative evaluation and quantitative evaluation, Herzberg's two-factor theory, Skinner's reinforcement theory, group dynamics theory.

\subsection{Seminar-Style Teaching Method}

Seminar-style teaching method is a kind of workshop, research class or research group. It is a form of academic communication that students discuss with a teacher to study a certain problem. The core is to fully explore the learning potential of the participants of the course, and maximize the learning potential. Conduct multi-angle and multi-level understanding of interactions, so as to deepen the understanding of a certain theme and achieve the best results of academic exchanges. The typical Seminar-style teaching structure is as follows:

(1) Introduction of supporters (generally held by teachers) (1-2 minutes). Announce the topic of discussion in this lesson, and do not make any prior statements on any related issues, in order to avoid thinking about other people's thinking about the problem;

(2) Thematic report presentation (25 minutes). Keynote speech by relevant reporters;

(3) The response of the observer (10 minutes). Speaking to the speaker's statement;

(4) Time-limited debate and communication (15 minutes). Around the theme, all participants put forward their own opinions on the speeches of the reporters and respondents, and the reporters and respondents can also provide supplementary explanations;

(5) Summary and comments (3-5 minutes). Commented by the hosted teacher.

The Organizational Link Design and the Teacher and student participation model research of this paper is based on this theory.

\subsection{Qualitative Evaluation and Quantitative Evaluation}

Qualitative evaluation is the method of not using mathematics, but based on the evaluator's observation and analysis of the usual performance, reality and state of the evaluation object or literature, and directly making a qualitative judgment on the evaluation object; Quantitative evaluation is the use of mathematical methods to collect and process data and to make quantitative judgments on the quantitative results of the evaluation objects.

The Review indicator system and measurement research of this paper is based on this theory.

\subsection{Herzberg's Two-Factor Theory and Skinner's Reinforcement Theory}

Herzberg's two-factor theory believes that the factors 
affecting the enthusiasm of employees can be divided into two categories: health care factors and incentive factors. The so-called health care factor refers to the factors that cause dissatisfaction among employees. Improving such factors can relieve the dissatisfaction of employees, but it cannot make employees feel satisfied and play a role in stimulating the enthusiasm of employees. The so-called incentive factors are the factors that make employees feel satisfied, mainly the job performance opportunities, the fun of the work itself, the sense of accomplishment at work, the expectation for future development, the sense of responsibility in the position, and so on. Only their improvement can satisfy the employees, thus giving employees higher incentives, mobilizing enthusiasm, and improving labor productivity.

Skinner's reinforcement theory holds that the behavior people take depends to a large extent on the outcome of the behavior. If the outcome of the behavior is in line with expectations or rewards, this result becomes a force to reinforce the behavior, thereby increasing the likelihood that the behavior will occur. Conversely, if the behavior brings bad results, then this behavior will subside. The focus of this theory is on correcting or changing the actual actions people take at work.

The Incentive design of this paper is based on this theory.

\subsection{Group Dynamics Theory}

The theory points out that people in the group pursue a sense of belonging to the community and form a complex interrelationship with each other, which in turn affects the behavior of people in the group and ultimately affects the behavior of the group. It can be seen that the factors that constitute the dynamics of group behavior mainly include the behavior, mutual influence and emotion of each person in the group. Through years of research, Lewin concluded that the group dynamic system includes cohesion, driving force and dissipative force. The first two elements are important factors for maintaining and promoting group development, while dissipative power is a negative factor for broken groups and should be avoided as much as possible. It is precisely because of the interaction, counterbalance and transformation of these three kinds of power that promotes the change and development of the group.

The Design of academic exchange platform of this paper is based on this theory.

\section{Results and Discussion}

\subsection{Organizational Link Design}

(1) Propaganda and call for papers. 3-5 months before the start of each "Graduate Academic Exchange Conference", various channels will be used to publish the enlightenment of the call for papers, and the enlightenment will be posted on the research hall and the college publicity board.

(2) Submission. Collect all manuscripts submitted before the deadline for submission, and summarize, sort, organize, and record.

(3) Participation survey. After receiving the manuscript, statistics will be made on the number of submissions and related student information to confirm how many people will participate in the first time. Then the classified articles are summarized, that is, the research content is sorted out, and then the summary results are released, and the second publicity and the call for papers are issued (in order to let the potential participants know what to tell in order to attract their submission and attend the meeting). And notify the person who has already participated to reconfirm whether they can attend the meeting.

(4) Summarize all the student information attending the meeting, select a suitable time for the meeting, invite as many teachers as possible and other teachers related to the content of the meeting, so that graduate students can participate as much as possible.

(5) Reviewer arrangements. Graduate students select papers for review according to their own interests, and arrange teachers to review papers in relevant fields. The review mainly involves the content of the papers and the evaluation of innovative reviews (the value of the selected questions, the standardization of the use of research methods, innovation, etc.). Finally, the final review comments and recommendations are given.

(6) Review of the written expression ability of the paper.

(7) On-site reporting and communication. The graduate students who submitted the papers made a short academic report on their papers at the meeting, and then all the graduate students who participated in the meeting gave their own opinions or suggestions, and the participating teachers gave their own comments on the relevant papers, and Give positive encouragement for the graduate students with deep insights.

(8) Review of the verbal ability of the report. It is mainly to cultivate graduate students' ability to speak and to express accurately and vividly.

(9) Description of the revision of the paper and summary of the meeting. The graduate organizer made a good meeting record during the meeting, and completely recorded all the reviewers' comments on each paper and timely feedback to the corresponding students. After the organizers will summarize the meeting, give a short question and answer to the graduate students and teachers attending the meeting, sum up the experience and lessons of the meeting, and aim to interact better in the next academic exchange meeting.

\subsection{Teacher and Student Participation Model Research}

This postgraduate academic conference aims to promote the cultivation of graduate students' innovative abilities. Therefore, it is intended to involve the students as the main body and participate in the whole process. The related roles and participating subject categories are shown in Table 1. 
Table 1. Annotation of this table.

\begin{tabular}{ll}
\hline Character & Participating subject category \\
\hline organizer & Postgraduates \\
Paper writing and reporter & Postgraduates \\
Participant of communication & Postgraduates and teachers \\
Paper content reviewer & Postgraduates, their tutors and other teachers \\
Written expression ability reviewer & Postgraduates, their tutors and other teachers \\
Speaking ability reviewer & Postgraduates, their tutors and other teachers \\
\hline
\end{tabular}

The core concept of this teacher-student participation is to conduct academic discussions on the equal concept of teachers and students, to provide students with a realistic platform for flying ideas, dare to speak and dare to think, and to really promote the cultivation of graduate students' innovation and expression skills.

The specific ways to participate are:

(1) The postgraduates who organize this conference introduce several research topics to be discussed at this conference (based on the classification of articles submitted by students who have previously compiled).

(2) Sub-topics allow postgraduates to submit their research content for about 15 minutes.

(3) The students ask questions about the reporter's article, about 15 minutes. During this period, the reporter can supplement his academic opinion, and the teachers should not make any speech to avoid restraining the students' thinking.

(4) The teachers comment on the research content of each student, and then the students ask questions again, about 10 minutes.

(5) The teachers and the students comment on the performance of the narrator in various aspects and fill in the corresponding score form in about 10 minutes. The postgraduates carefully record the comments of the teachers and students, which is convenient for students to modify later.

(6) After the meeting, a postgraduate gave a brief summary of the meeting, about 5 minutes.

\subsection{Review Indicator System and Measurement Research}

According to the research of domestic and foreign literatures, the main evaluation indicators for engineering papers are innovation, science, practicality, research methods and research value. This paper conducts a normative study, which indicators should be used in the evaluation of academic papers, and adopts a combination of qualitative evaluation methods and quantitative evaluation methods. The quantitative evaluation method combines the literature and the research objectives, and evaluates the six aspects of the topic selection, verbal ability, article normativeness, article innovation, written expression ability and communication ability. Because the quantitative evaluation method is embodied in the last "level" of the paper, the evaluation index system and measurement conforming to the "Graduate Academic Exchange Conference" are compiled and developed. The design adopts the percentage system, and the detailed contents and forms are shown as fellows.

Table 2. Design of the evaluation forms for the topic of the papers of the graduate academic exchange conference.

\begin{tabular}{ll}
\hline Topic (15\%) & Criterion \\
\hline $13 \%-15 \%$ & The topic is novel, has a certain frontier, and has strong practical application value or theoretical value. \\
$10 \%-12 \%$ & The topic has certain new ideas and has certain practical application value or theoretical value. \\
$6 \%-9 \%$ & There is no new idea in the topic \\
Less than $6 \%$ & The topic is highly similar to others and lacks a correct understanding of the topic. \\
\hline
\end{tabular}

Table 3. Design of the evaluation forms for the oral ability of the graduate students.

\begin{tabular}{ll}
\hline Oral ability (15\%) & Criterion \\
\hline $13 \%-15 \%$ & $\begin{array}{l}\text { In the process of communication, the ideas are clear, the expressions are concise and clear, and they can accurately explain their ideas } \\
\text { and communicate effectively. }\end{array}$ \\
$\begin{array}{l}\text { Clear expression, clear thinking during communication, others can clearly understand what to express, speed of speech is appropriate, } \\
\text { but expression is not concise } \\
\text { The expression is basically clear, the ideas in the communication process are not clear, but others can roughly understand what to } \\
6 \%-9 \%\end{array}$ & $\begin{array}{l}\text { express. } \\
\text { The expression is not clear what you want to express, the way of communication is not clear, others cannot understand what to express }\end{array}$ \\
\hline
\end{tabular}

Table 4. Design of the evaluation forms for the article normative of the papers of the graduate academic exchange conference.

\begin{tabular}{ll}
\hline Topic (15\%) & Criterion \\
\hline $13 \%-15 \%$ & $\begin{array}{l}\text { Contents, abstracts, keywords, texts (including introductions, thesis topics and conclusions), references, fonts and charts, and articles } \\
\text { are in line with the requirements. }\end{array}$ \\
$\begin{array}{l}\text { Contents, abstracts, keywords, texts (including introductions, thesis topics and conclusions) meet the requirements, the references are } \\
\text { basically appropriate, fonts and charts, and the layout of the articles basically meets the requirements. } \\
\text { Contents, abstracts, keywords, texts (including introductions, thesis topics and conclusions) meet the requirements, the references are } \\
\text { not sufficient, fonts and charts, and the layout of the articles has individual problems. }\end{array}$ \\
$\begin{array}{l}\text { Table of contents, abstracts, keywords, text (including introductions, thesis topics and conclusions) do not meet the requirements, too } \\
\text { few references, fonts and charts, the layout of the article is obviously wrong }\end{array}$ \\
\hline
\end{tabular}


Table 5. Design of the evaluation forms for the innovation of the papers of the graduate academic exchange conference.

\begin{tabular}{ll}
\hline Topic (25\%) & Criterion \\
\hline $22 \%-25 \%$ & Research methods and content are novel, and the research results are original \\
$18 \%-21 \%$ & The research method and content are relatively new, and the problems in other people's articles are improved and larger or other results are \\
& found and correct. \\
$12 \%-18 \%$ & There is no innovation in research methods and content, but some problems have been improved for others, and the results are correct. \\
Less than $12 \%$ & There is no innovation in research methods and content, plagiarizing other people's articles or getting wrong conclusions \\
\hline
\end{tabular}

Table 6. Design of the evaluation forms for the written ability of the graduate students.

\begin{tabular}{ll}
\hline Topic (15\%) & Criterion \\
\hline $13 \%-15 \%$ & $\begin{array}{l}\text { The research ideas of the article are clear, the content is well-founded, the experimental methods or simulation methods are used properly, } \\
\text { and the results are correct and reliable, reflecting the author's solid theoretical foundation and strong scientific research ability. }\end{array}$ \\
$\begin{array}{l}\text { The research of the article is clear, the content is reasonable, the experimental method or the simulation method is applied in general, and } \\
\text { the result is correct and reliable, which reflects the author's certain theoretical foundation and research ability. }\end{array}$ \\
$\begin{array}{l}\text { The research ideas of the article are general, and the experimental methods or simulation methods used are somewhat unsuitable, and the } \\
\text { results obtained are more biased. }\end{array}$ \\
The research ideas adopted in the article are unreasonable, and the experimental methods or simulation methods used are improper.
\end{tabular}

Table 7. Design of the evaluation forms for the communication skills of the graduate students.

\begin{tabular}{|c|c|}
\hline Topic (15\%) & Criterion \\
\hline $13 \%-15 \%$ & $\begin{array}{l}\text { Actively raise your own questions about other people's research content and other ideas about their own research content, and be able to } \\
\text { communicate effectively with others. }\end{array}$ \\
\hline $10 \%-12 \%$ & Actively ask your own research content or other ideas about others' research content, and communicate with others \\
\hline $6 \%-9 \%$ & $\begin{array}{l}\text { Occasionally ask questions about other people's research content or other ideas about others' research content, and communicate } \\
\text { effectively with others. }\end{array}$ \\
\hline Less than $6 \%$ & Hardly have any questions or ideas about other people's research content, just listening to others' thoughts silently. \\
\hline
\end{tabular}

\subsection{Incentive Design}

The construction of postgraduate academic conferences is a dynamic, long-term, continuous improvement work. Therefore, the necessary incentive mechanism is essential, which can effectively improve the participation of students. Based on Herzberg's two-factor theory [5] and Skinner's reinforcement theory [5], this paper designs the following incentives.

In order to improve the participation of the students, different material rewards are given to students who have obtained different levels.

(1) Excellent, reward Li Ning badminton racket 1 or Double Happiness table tennis single shot; good, reward dormitory mini fan; pass, reward mobile phone tempered film or mobile phone case.

(2) For the first time to obtain excellent students, the college will issue the "Excellent Paper Award" honorary certificate, and with the record of student information, the college should also provide policy support for students with strong academic ability, for example, to participate in academics at home and abroad. The meeting will give priority to setting up special funds for academic exchange meetings.

(3) For the students who have obtained good grades, after reviewing the papers and reviewing them with their tutors or other teachers, if the content of the papers is excellent, they will also receive the "Excellent Paper Award" certificate from the college, and will receive fewer funds.

The student's thesis must be revised repeatedly. After each revision, the instructor or other teacher should be reviewed again until they reach the level that can be published.

\subsection{Design of Academic Exchange Platform}

The design of the academic exchange platform aims to cultivate postgraduate innovation and expression skills, provide a good academic exchange platform, create an academic atmosphere with a strong teaching experience, and provide a platform for graduate students to answer their doubts in scientific research in a timely manner.

The design of the graduate academic exchange platform is divided into an online communication platform and an offline communication platform. The online communication platform is mainly in the form of a network. The offline communication platform mainly organizes some academic activities on a regular basis.

The main ways of online communication platform are as follows:

(1) Build a sub-forum and college general forum composed of different majors of the college, invite teachers from different disciplines of the college to join, help students to answer questions that cannot be answered between each other; build a school forum, invite teachers and students to join, different colleges Teachers and students can share some of the latest research in this field in the forum. This can greatly expand the students' horizons and help students think about their research topics with a different academic perspective. Through the establishment of the forum, the relationship between teachers and students is closer, and a good academic atmosphere is created, which contributes to academic crossover, develops students' academic horizons, learns different theories and methods, and stimulates their innovative ability.

(2) Establish a QQ group in the laboratory to understand the 
research direction of the laboratory students.

The main methods of the offline communication platform are as follows:

(1) Schools should adopt programs with students with different professional backgrounds, which will help to expand the knowledge of students and help them to carry out their own research projects.

(2) Regularly hold academic exchange activities, and timely communication between students and teachers can not only enhance students' communication and communication skills, but also enhance their academic level. In order for the academic exchange platform to continue to develop, there should be certain incentives. For online communication platforms, for students who answer other people's questions in the forum and successfully help others to answer questions, the college or school should give certain material rewards or honorary rewards; for teachers, schools or colleges should establish a reasonable mechanism to enable teachers to actively answer questions from students. For example, it is linked to personal performance. For offline communication platforms, colleges or schools should give students or teachers who actively participate in academic exchange activities appropriate policy preferences and increase their participation.

Through the design of the above program and the holding of the conference, the following problems were found:

(1) Sorting the submitted articles and allowing interested students to review the articles to a certain extent stimulated the enthusiasm of the students to participate in the meeting and the critical thinking ability of the students, but due to the differences between the subjects, students from different academic backgrounds sometimes ask each other questions as simple questions about some basic concepts. Therefore, when the next meeting is held, it is necessary to first publish the issues to be discussed at the meeting, and provide some relevant materials, so that students can get the basic knowledge in advance and participate in the meeting better.

(2) The writing ability of students' papers needs to be improved. Some graduate students have problems in the format of writing papers. For the problem of non-standard writing, it can be solved by letting the relevant teacher tell the requirements about the writing format of the paper.

(3) Students' ability to review manuscripts needs to be strengthened. The review process of the paper should be strengthened when preparing for the next meeting, because some graduate students are not so much experienced on reviewing manuscripts.

\section{Conclusion}

Through the above-mentioned design of the academic conference for graduate students, the conference organizing committee convokes a conference aiming at the academic expressing and communication of graduate students in school of automotive engineering. The results showed that the original design for the academic conference is successful. However, in order to better organize the next meeting, certain measures should be taken to strengthen students' critical thinking ability, essay writing ability and reviewing ability.

\section{Acknowledgements}

The authors would like to thank the support from Graduate Education Reform Research Project of Harbin Institute of Technology (No. JGYJ-2017049).

\section{References}

[1] Zhaohui Chu. The concept and operation of postgraduate academic activities In Chinese. Degree and postgraduate education, 2003 (1): 42-45.

[2] Wenjie Shen, Qiang Zhu. Seminar Teaching Method: A New Mode of Postgraduate Teaching In Chinese. 2002 (z2): 43-47.

[3] Fischer, Charles C...Managing Your Research Writing for Success:Passing The "Gatekeepers". Journal of business\&entrepreneurship. 2004, 4 (1), 115-123.

[4] Baopeng Feng, Pingfa Gao, Hongwei Su. On the construction of postgraduate innovation incentive mechanism In Chinese. Degree and postgraduate education, 2008 (s1): 82-86.

[5] Chungui Li. Study on the Countermeasures to Improve the Incentive Mechanism of College Teachers in China In Chinese [D]. Changsha: Hunan University,2010.

[6] Limin Yang, Qingju An, Liang Wang. On the Construction of Academic Exchange Platform for Graduate Students In Chinese [J]. Journal of Qingdao University of Science and Technology (Social Sciences), 2006, 22 (1): 110-113.

[7] Yuyu Bai, Guangjun Zhang. Construction and Practice of Postgraduate Academic Exchange System In Chinese. Journal of Beijing University of Aeronautics and Astronautics (Social Science Edition), 2009, 22 (s1): 9-12.

[8] Jie Wu. Research on the Construction of Academic Exchange Platform for Graduate Students in Research-oriented Agricultural University-Taking Huazhong Agricultural University as an Example In Chinese [D]. Wuhan: Huazhong Agricultural University, 2012.

[9] Yang Xia, Xiaoting Qu. Academic Activities and the Cultivation of Graduate Students' Innovative Quality In Chinese. China Electric Power Education, 2004 (z1): 76-79.

[10] Ling Zhou, Guohua Yan. The Construction and Implementation of Academic Exchange Platform for Liberal Arts Graduates in Universities of Science and Engineering In Chinese [J]. ournal of Beijing Institute of Technology(Social Science Edition), 2006, 8 (3): 98-101.

[11] Yuying Xiong, Jiajie Wu. Actively carrying out academic exchange activities to enhance the innovation ability of graduate students In Chinese [J]. Science and Technology Journal, 2016, 19: 64-65.

[12] Ya Zhao. Investigation and Analysis of Academic Academic Atmosphere and Its Influencing Factors In Chinese [D]. Suzhou: Suzhou University, 2010.

[13] Lingfang Hu. Research on the Evaluation Standards of Academic Papers in China In Chinese [D]. Wuhan: Huazhong University of Science and Technology, 2009. 